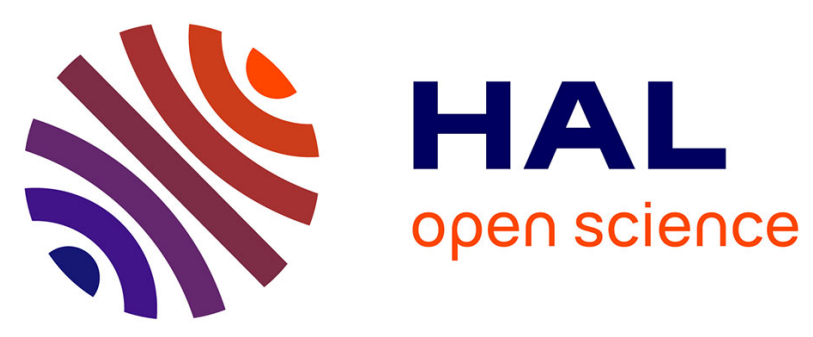

\title{
Social status and health: a comparison of British civil servants in Whitehall-II with European- and African-Americans in CARDIA.
}

\author{
Nancy Adler, Archana Singh-Manoux, Joseph Schwartz, Judith Stewart, \\ Karen Matthews, Michael G Marmot
}

\section{To cite this version:}

Nancy Adler, Archana Singh-Manoux, Joseph Schwartz, Judith Stewart, Karen Matthews, et al.. Social status and health: a comparison of British civil servants in Whitehall-II with Europeanand African-Americans in CARDIA.. Social Science and Medicine, 2008, 66 (5), pp.1034-45. 10.1016/j.socscimed.2007.11.031 . inserm-01161860

\section{HAL Id: inserm-01161860 https://www.hal.inserm.fr/inserm-01161860}

Submitted on 22 Jun 2015

HAL is a multi-disciplinary open access archive for the deposit and dissemination of scientific research documents, whether they are published or not. The documents may come from teaching and research institutions in France or abroad, or from public or private research centers.
L'archive ouverte pluridisciplinaire HAL, est destinée au dépôt et à la diffusion de documents scientifiques de niveau recherche, publiés ou non, émanant des établissements d'enseignement et de recherche français ou étrangers, des laboratoires publics ou privés. 
Social status and health: a comparison of British civil servants in Whitehall-II with European- and African-Americans in CARDIA.

Nancy Adler ${ }^{\mathrm{a}}$, Archana Singh-Manoux ${ }^{\mathrm{b}}$, Joseph Schwartz ${ }^{\mathrm{c}}$, Judith Stewart ${ }^{\mathrm{a}}$, Karen Matthews $^{\mathrm{d}}$, Michael G. Marmot ${ }^{\mathrm{b}}$ a University of California at San Francisco, San Francisco, CA, USA b University College London, London, UK c Stony Brook University, Stony Brook, NY, USA d University of Pittsburgh, Pittsburgh, PA, USA 


\section{ABSTRACT}

Socioeconomic status (SES) is related to health in every industrialized society where it has been studied. Indicators include educational attainment, occupational status, and income. Subjective social status (SSS) is a summative judgment of one's socioeconomic position across these dimensions and appears also to be associated with health status. The current study uses a visual analogue of a ladder to capture SSS. It examines whether SSS has similar associations with SES indicators and with health outcomes among British civil servants (participants in the Whitehall-II study), and U.S. whites and blacks (participants in the CARDIA study). The comparisons shed light on social status in the U.S. and England and on the applicability of findings from Whitehall-II to both whites and blacks in the U.S.

Parallel analyses in each group examined (1) the extent to which income, education, and occupational status determine SSS ratings, (2) the association of SSS with hypertension, depression, and global health, and (3) the extent to which adjustment for education, occupation and income individually and collectively reduce the association of SSS and health outcomes. As predicted, occupation is a more important determinant of SSS in Whitehall-II than in CARDIA; adjustment for occupation reduces the association between SSS and health outcomes more for the Whitehall-II participantsespecially males-than for CARDIA participants. Among the latter, education and income play a relatively greater role. Socioeconomic factors do not predict SSS scores for blacks as well as they do for the other two groups. SSS is significantly related to global health and depression in all groups and to hypertension in all groups except black males. Overall, relationships of SSS and health were stronger for Whitehall-II and white CARDIA participants than for blacks in CARDIA. 
Within the burgeoning literature on health disparities, a small set of studies have documented that people's own assessments of their global socioeconomic status relate to their health. Lower subjective social status (SSS) has been found to be associated with poorer self-reported global health across the age range, to poorer functional status among older people and to obesity and depression among youth (Goodman, Adler, Daniels, Morrison, Slap, \& Dolan, 2003; Hu, Adler, Goldman, Weinstein, \& Seeman, 2005; Operario, Adler \& Williams, 2004; Ostrove, Adler, Kuppermann, \& Washington, 2000; Singh-Manoux, Adler, \& Marmot, 2003). Lower SSS is also associated with biological risk factors including increased heart rate, greater abdominal fat deposition, greater morning rise in cortisol, and greater susceptibility to infection following exposure to a rhinovirus (Adler, Epel, Castellazzo, \& Ickovicks, 2000; Cohen, Alper, Doyle, Adler, Treanor, \& Turner, in press; Wright \& Steptoe, 2005).

A measure of SSS using a symbolic social ladder to allow individuals to place themselves relative to others in the society was included in Wave 5 of the Whitehall-II study of British civil servants. SSS was significantly related to global self-rated health, depression, respiratory disease and diabetes, also assessed in Wave 5. These associations were largely, though not completely, accounted for by the components of objective socioeconomic status-occupational grade, education and income to which the "ladder" is keyed (Singh-Manoux et al., 2003). SSS also predicted subsequent change in overall health status over approximately three years, and when subjective and objective status were entered simultaneously only SSS remained as a significant predictor of change in health status (Singh-Manoux, Marmot, \& Adler, 2005).

The inclusion of the ladder in Whitehall-II allows for comparisons with other populations. The Whitehall studies have been a rich source of data on social disparities in health. The finding of a graded association between employment grade and mortality (Marmot, Shipley, \& Rose, 1984) demonstrated the power of socioeconomic status 
(SES) to influence health all across the SES spectrum. Data from other countries also show gradients between SES (generally measured by income or education) and health. Direct comparisons of findings with Whitehall are difficult since the primary SES measure in Whitehall, employment grade, is specific to the civil service. This paper evaluates the comparability of findings from Whitehall-II and a U.S. community-based sample (CARDIA). It examines the extent to which the components of SES contribute to subjective status and its association with health and the relationship of SSS and health in these populations.

Generalizability from Whitehall to the U.S. Marmot, Ryff, Bumpass, Shipley, \& Marks (1997) found similar relationships between SES and health in Whitehall and two U.S. samples: the Wisconsin Longitudinal Survey (WLS) and the National Survey of Families and Households (NSFH). However, there are still reasons to examine whether Whitehall results can generalize fully to the whole U.S. population

First, a major difference between Whitehall and U.S. populations is the racial/ethnic make-up. The Whitehall sample is primarily white. It remains an open question how well Whitehall results can be generalized to groups such as African Americans in which experiences of discrimination based on race/ethnicity are confounded with SES and contribute to poorer health (Williams, 1999). Since the WLS itself has little ethnic diversity and analyses of the NSFH used race/ethnicity as a control rather than being examined directly, the study by Marmot et al. (1997) does not show the applicability of Whitehall findings to minority populations.

Secondly, because of sampling and measurement differences, associations of specific components of SES may differ; Whitehall data may underestimate the effects of income and overestimate occupation in comparison to community-based data. Whitehall has truncated variation in income; the sample of civil servants does not include the 
poorest and the wealthiest segments of the population. At the same time, the precise measurement of occupational grade may result in relatively stronger associations of health with occupation than will be found in the U.S. where the predominant occupational measure is the Duncan Socioeconomic Index, the SEI (Duncan, 1961). The SEI reflects relative prestige of specific occupations and the sociodemographic characteristics of individuals in those occupations. These and other factors can vary considerably from one work setting to another, rendering the SEI a less valid measure of job conditions than employment grade. Employment grade is measured with virtually no error and participants are part of the same organization and know where they stand relative to others. Thus, the occupation component of SES may be more strongly related to outcomes in Whitehall than in U.S. community samples. The precise measure also affects the relative strength of association of the SES indicators with health. In Whitehall but not in other samples, occupation is measured with less error than are income and education and occupation is likely to show stronger relationships with health outcomes than will income or education. This is less likely to be the case in community samples.

Finally, there may be cultural differences beyond differences in sampling and measurement. Fuhrer, Shipley, Chastang, Schmaus, Niedhammer, Stansfeld, et al. (2000) compared employees of a large French utility company to Whitehall-II. Although they found a similar gradient in both samples between occupational level and self-rated health, there were country-specific differences in behavioral and psychosocial predictors of health. The authors speculated these were the result of cultural differences in evaluations of self-rated health. Differences seem likely between England and the U.S. in evaluations of and responses to social position. In contrast to England, where social class is the most commonly studied basis of social stratification, the focus in the U.S. has primarily been on race/ethnicity (Kawachi, Daniels, \& Robinson, 2005). Additionally, 
although actual social mobility may be no greater in the U.S., there is a strong cultural belief that it is, and popular culture often represents the British as more cognizant of class differences. The U.S. has "an inherited ideology of classlessness" (Bottomore, 1965, p. 51). To the extent that social class is more salient and central to identity in England lower social status may engender stronger negative social emotions (Marmot, 2006) and SSS should show a stronger association with health among the British than among Americans.

The bases of social position may vary between the countries as well. In contrast to British aristocracy where status is inherited and may not have economic concomitants, U.S. "'aristocracy" has been defined primarily by great wealth. Horatio Alger and other self-made men remain cultural icons. To the extent that this is internalized, income may be more strongly related to SSS in the U.S. than in England.

Taking these differences together, we would expect a stronger association of SSS with health in Whitehall-II than in a U.S. sample and that SSS is relatively more strongly linked to occupation in Whitehall-II and to income in the U.S.

Subjective social status. Comparisons of SES effects across countries are complicated by differences in educational systems, occupational structures, and in the implications of income levels for purchasing power. The SSS measure, which uses the visual analogue of a ladder to allow individuals to indicate where they stand in relation to others in their country on income, education and occupation, allows direct comparison of social standing and its relationship to health across countries. Associations of SSS and health have been found in countries ranging from the U.S. and England to Hungary, Mexico, China, and Taiwan. SSS appears to capture objective socioeconomic conditions (SinghManoux et al., 2003), and may provide a more nuanced measure. In several studies, SSS ratings showed an independent association with health when adjusted for objective 
SES (e.g., Goldman, Cornman, \& Chang, 2002; Wright \& Steptoe, 2005; Ostrove et al., 2000; Cohen et al., in press). Indicators of objective SES have substantial "noise." Income is a sensitive topic and is often assessed in broad categories. Unless accompanied by measures of wealth, it also may not capture people's true economic resources. Occupation is a complex variable; there is no consensually agreed-upon classification of jobs and characterizations of a given occupation may not reflect the conditions of a specific job. Even educational attainment, which is relatively clear, is limited since it does not take into account quality of the education. When making SSS ratings, individuals may factor in these other considerations.

Perceptions of low status may themselves be sources of stress and engender health-damaging negative emotions such as shame (Marmot, 2006; Dickerson, Gruenewald, \& Kemeny, 2004). Recent brain imaging data reveals that individuals lower on SSS have diminished grey matter in a region of the brain linked to emotion and stress reactivity. Neither individual income and education nor community-level SES were related to grey matter volume in this region and the association of SSS and reduced volume remained when controlled for those variables and for depressive symptoms and negative affect (Gianaros, Horenstein, Cohen, Matthews, Brown, Flory, et al., 2007).

Associations between SSS and self-rated health could be artifactual, due to mono-method bias contributing to shared variance between self-report of social status and of health, or to confounding of negative affect with SSS and self-rated health. However, research showing the persistence of the relationship of SSS and self-rated health when adjusted for negative affect (e.g., Operario et al., 2004) and the association of SSS with biological indicators argue against this explanation.

Race/ethnicity. In the U.S., measurement of SES is complicated by the interaction of SES with race and ethnicity. SES measures may be less valid indicators of resources and social status for blacks than for whites. Income and education don't 
appear to provide the same benefit to the former as for the latter. For example, at the same level of income, blacks have fewer financial material resources than do whites (Oliver \& Shapiro, 1995). Similarly, schools serving black children often have fewer resources, and the same level of educational attainment may confer fewer economic benefits. Moreover, because of discrimination based on race/ethnicity, social status may be less tightly linked to objective SES among blacks than among whites. For these reasons, SSS may be less strongly associated with objective indicators of SES among blacks. It also appears that SSS is less strongly linked to health among blacks. In multivariate models including education, household income, and SSS as predictors of self-rated health among pregnant women in the U.S., Ostrove et al. (2000) found that SSS was the only significant independent predictor for white and Chinese American women, while for Latina and African American women income was the only significant predictor.

Current paper. The current paper compares British civil servants in the Whitehall-II study and white and black participants in the CARDIA study in the U.S. to address three issues. One is the role of social position in the two societies. To the extent that social class is more central to identity in England than in the U.S., perceptions of lower status may be relatively more emotionally charged and ladder rankings should have a stronger association with health among British than among American subjects, (e.g., stronger "zero order" relationships with health indicators, and a stronger association when adjusted for objective indicators).

A second issue is whether occupation plays a relatively greater role in WhitehallII findings than in CARDIA. If occupation is a more salient aspect of status in WhitehallII, it should show a stronger association with SSS and reduce the association of SSS and health to a greater degree when controlled for. In addition, there should be a 
stronger association of employment grade relative to income and education within Whitehall-II than for occupation relative to income and education within CARDIA.

A third issue is whether Whitehall-II findings are more applicable to whites than to blacks in the U.S. Since Whitehall-II subjects are predominantly white, findings from white CARDIA participants are likely to be more comparable to Whitehall-II findings than those of black participants. It will be of interest to see if the white CARDIA subjects show patterns more like the Whitehall-II participants with whom they have race/ethnicity in common, or more like their black country-mates.

We test the following:

Hypothesis 1. The strongest predictor of SSS will be occupation in Whitehall-II and income in CARDIA.

Hypothesis 2. SSS ratings will be more strongly related to health outcomes among Whitehall-II than among CARDIA participants. A related question is whether associations are similar for white and black CARDIA subjects. Hypothesis 3. The association of SSS and health will be reduced more when adjusted for occupation in Whitehall-II than in CARDIA. In addition, in WhitehallII adjusting for occupation will result in a greater reduction than will adjustment for income or education, while in CARDIA adjustments for income or education will result in a greater reduction in this association than will adjustment for occupation.

\section{Participants and methods}

\section{Participants}

WHITEHALL-II is a longitudinal study of British civil servants and has been described extensively elsewhere. Singh-Manoux et al. (2003) previously reported associations between SSS and prevalence of angina, diabetes, respiratory illness, self- 
reported global health and depression among 4609 men and 2372 women age 47-67 studied in Wave V. Some of those data are included in this study, along with new analyses on hypertension.

CARDIA is a longitudinal study of the development of cardiovascular risk factors and disease. Individuals were recruited at four U.S. sites: Birmingham; Chicago, Minneapolis, and Oakland. Community samples were recruited at the first three sites; Oakland participants were drawn from enrollees in a prepaid health plan, Kaiser Permanente. The initial sample was stratified at each site by gender (male/female), race (black/white), and education (high school graduate or less versus some college or more).

The current analyses utilized Year 15 data from 1003 black women, 1025 white women, 703 black men and 901 white men ranging in age from 33 to 48 years. We replicated in CARDIA prior analyses from Whitehall-II on perceived general health and depression, and conducted new analyses in both samples on hypertension. New analyses were done in both studies on SES determinants of SSS.

\section{Measures}

Subjective socioeconomic status (SSS). CARDIA subjects were provided a graphic of a ladder with 9 rungs, with instructions to imagine that it represented where people stand in the United States, with those at the top of the ladder being the best-off (most money, most education, and most respected jobs) and those at the bottom being worst off. They placed an "X" on the rung indicating their position in this hierarchy. The same measure, though with 10 rungs and a reference to where people stand in society, was used in the Whitehall-II.

\section{Objective socioeconomic indicators.}


Occupation was assessed in CARDIA by the SEI, a revised version of Duncan's socioeconomic index created by Stevens and Cho (1985). The parallel measure in Whitehall-Il was employment grade.

Income was assessed in both samples by household income. In CARDIA, respondents indicated which of 9 categories (from less than $\$ 15,000$ to $\$ 100,000$ and over) represented their total combined family income for the last 12 months. Whitehall-II respondents chose one of 11 categories ranging from less than $£ 999$ to $£ 200,000$ and over.

Education was assessed by the highest credential obtained. There were 6 categories running from less than high school or equivalency to professional degree. Whitehall-II had 5 levels from no formal education to higher than first university degree.

\section{Health outcomes.}

We examined three different health outcomes. Global health provides a summative measure of an individual's health; these evaluations have been shown to have strong predictive validity even when adjusted for known health risks. Depression provides an assessment of mental health, and hypertension provides a measure of health risk which is not based solely on self-report.

Depression was assessed in CARDIA by the CES-D (Radloff, 1977) and in Whitehall-II by the depression items on the GHQ (Goldberg, 1972). These measures are widely used in their respective countries to screen for risk of depression. A sample of older community residents completed both measures and each performed well in identifying individuals who were depressed (based on a clinical interview); they had similar rates of false positives (Papassotiropoulos \& Huen, 1999). Standardized cut-offs (e.g., above 5 on the GHQ and above 16 on the CES-D) were used to define "cases" versus "non-cases" in Whitehall-II and CARDIA. 
Global health was assessed in both samples by the single item, "In general would you say your health is: excellent, very good, good, fair or poor." Responses were dichotomized into reporting good to excellent health versus fair or poor health.

Hypertension was determined from blood pressure readings taken during medical exams given each participant. They also reported all medications they were taking and those reporting antihypertensive medications were assumed to have the underlying condition of hypertension. Thus for both samples, hypertensive "cases" were defined as those with systolic/diastolic blood pressure exceeding $135 / 85 \mathrm{mmHg}$ or reporting current use of antihypertensive medications.

Statistical analyses. First SSS was regressed on the three components of objective SES in each group to determine the relative contribution of income, education and occupation to subjective status. For other analyses we employed the same analytical procedures used by Singh-Manoux et al. (2003) to assure comparability with the Whitehall-II study. Ladder scores were grouped into five categories and the prevalence of depression and poor health, standardized for age (using the direct method and the age distribution for the full CARDIA sample), were calculated separately for white and black men and women in CARDIA. In addition, the prevalence of hypertension (not examined previously) across SSS was calculated for all groups. The associations between health outcomes (scored as absent/present) to SSS were tested by logistic regression, controlling for age. The Relative Index of Inequality (RII) compares the predicted odds ratio of a given outcome for those at the lowest versus highest levels based on the overall distribution, and $95 \%$ confidence intervals are presented. We examine four additional models, adjusting for age and: 1) education, 2) occupation, 3) income and 4) all three SES indicators. This shows the degree to which the RII can be accounted for by each component of SES as well as by all three indicators together. 
The significance of the differences in the Rlls between groups was tested by calculating an estimate of the standard error of the difference in RIls (equals the square root of the sum of the squared standard errors of each group's RII) and using this to calculate a tstatistic defined as $\left(R \|_{1}-R I_{2}\right)$ / se, and evaluating this against the t-distribution with $\mathrm{df}=\mathrm{n}_{1}+\mathrm{n}_{2}-4$.

Those who were missing data on SSS or any of the three objective SES measures $(3.0 \%$ of the CARDIA sample; X.X\% of the Whitehall II sample) were excluded from all analyses. Those missing data on a particular health measure $(1 \%$ for CESD and $0.3 \%$ for hypertension status in CARDIA) were excluded from the analysis of that measure only. Analyses were conducted using SAS, version 8.2.

Results

Distribution of subjective status.

Table 1 shows how each subgroup in CARDIA (white and black men and women) and Whitehall-II men and women placed themselves on the SSS ladder. Black men and women from CARDIA were more likely to place themselves on the lowest rungs of the ladder and less likely to place themselves on the $7^{\text {th }}$ or $8^{\text {th }}$ rungs compared to Whitehall-II respondents and to whites in CARDIA. White women in CARDIA were less likely than the other groups to place themselves at the top of the ladder. Since there were 9 rungs in the CARDIA ladder and 10 in Whitehall-II, a smaller number of CARDIA relative to Whitehall-II participants might be expected to be in the top category. Despite this, it appears that respondents, regardless of group, arrayed themselves in a roughly similar way on the ladder.

\section{Predictors of SSS}


Hypothesis 1 predicted that occupation as measured by employment grade would be the strongest predictor of SSS among Whitehall-II participants, but that income would be relatively more important for CARDIA subjects. Table 2 provides the correlations between ladder scores and each of the three components of SES for the six groups. As expected, occupation correlates more strongly with SSS for Whitehall-II participants (.56 for women and .58 for men) than for any CARDIA group. Correlations for white CARDIA women and men (.28 and .35 respectively) are intermediate between those of Whitehall-II subjects and black CARDIA subjects (.15 and .11 for women and men respectively). Also as predicted, income showed the strongest correlation with SSS for CARDIA subjects. The correlations of all of objective measures with SSS were weakest for blacks in CARDIA.

Regressions predicting ladder scores from the objective indicators confirm, the relative importance of occupation in Whitehall-II (see Table 3). For Whitehall-II men and women, the strongest predictor of SSS by far is occupation, while for all four CARDIA groups, occupation is not significantly related to SSS. For white men and women and for black men, income is the strongest determinant of their subjective status; for black women it is education. The traditional measures of SES account for about a third of the variance in SSS for Whitehall-II subjects and for whites in CARDIA but relatively little for CARDIA black men and women.

\section{Prevalence of health problems by SSS.}

Hypothesis 2 predicted that SSS would be more strongly related to health among Whitehall-II than among CARDIA subjects. Table 4 presents the prevalence of the three health problems at each of the five levels of SSS. The significance of the associations shown in the last column is consistent with results using the RII shown in the first column in Tables 5-7 for the same outcomes. The RII represents the predicted odds ratio of 
worse health for those in the bottom category compared to those in the top category of SSS which is based on the linear trend across the whole distribution of SSS. As reported previously by Singh-Manoux et al. (2003), lower SSS was associated with a greater age-adjusted prevalence of poor global health and depression among both men and women in Whitehall-II, and results show that this occurs for all four CARDIA groups as well. New analyses of hypertension reveal significantly higher prevalence of hypertension among those with lower SSS for all groups in Whitehall-II and CARDIA except for black males.

Unexpectedly, however, the RIls are generally higher among CARDIA participants than in Whitehall-II. The association of SSS with poor global health is significantly greater among both groups of CARDIA women (RII=43.3 and 21.3 for whites and blacks respectively) compared to Whitehall-II women (RII=3.76). Among men, the association is significantly greater for CARDIA white men (RII=23.6) than for Whitehall-II men (RII=4.16); black men are intermediate (RII=5.89).

SSS shows a much stronger relationship with depression for CARDIA white women $(R I I=31.3)$ than for either of the other two groups of women and the association is stronger for CARDIA black women (R\|=9.10) than for Whitehall-II women (R\|=2.65). Among men, there is no difference between the CARDIA groups (RIIs=6.24 and 6.91) and both show significantly stronger relationships than do the Whitehall-II men $(\mathrm{RII}=1.78)$.

For all groups except black men in CARDIA, the prevalence of hypertension is significantly greater for those lower on the ladder. For both sexes, whites in CARDIA exhibit stronger associations of SSS and hypertension than do either blacks or Whitehall-II participants, who do not differ from one another. For women the respective RIls for hypertension for CARDIA white, CARDIA black and Whitehall-II subjects are 7.34, 2.29 and 1.71. For men these are 4.82, .78, and 1.27. 


\section{Adjusting for objective SES.}

Hypothesis 3 predicted that occupation as measured by employment grade in Whitehall-II would cause a greater reduction in the relationship of SSS and health when controlled for than would occur for the CARDIA groups. Additionally, within Whitehall-II we predicted a greater reduction in the RII when adjusted for occupation than when adjusted for income or education, while this difference was not expected for CARDIA. Though not evaluated in terms of statistical significance, one can see from Tables 5-7 that the reduction in the RII when adjusted for occupation (second column) is greater for Whitehall-II men than for CARDIA men for all three outcomes and for Whitehall-II women than CARDIA women for hypertension. The reduction indicates how much of the association of SSS with the health outcome is due to the overlap of SSS with that measure of SES. For hypertension (Table 5), adjusting for occupation causes a $65 \%$ reduction in the RII for women and $52 \%$ for men in Whitehall-II. This compares in CARDIA to only a $24 \%$ reduction for white men and a negligible reduction for both black and white women. Since the odds of hypertension were not increased by low SSS for black men, no further analyses were done for this group. For general health and for depression (tables $6 \& 7$ ) adjustment for occupation causes the greatest reduction in the RII for Whitehall-II men (reductions of $47 \%$ and $49 \%$ respectively). However, for general health adjustment for occupation causes a comparable reduction in the RII for CARDIA white women (46\%) and less for Whitehall-II women and for CARDIA black men and women (15-25\%) there was virtually no effect for CARDIA white men. The pattern for depression is more complicated, including an increase in the RII for Whitehall-II women and CARDIA white men when adjusted for occupation.

The second prediction was that in Whitehall-II but not CARDIA, adjustment for occupation would reduce the RII more than would adjustment for income or education. For hypertension, there is a comparable reduction in RII for Whitehall-II men and women 
when adjusted for occupation (52\% and $65 \%$ respectively) as for income (52\% and $62 \%$ respectively). Adjustment for education has no effect for Whitehall-II women (-1\%) and reduction of only $26 \%$ in the men. In contrast, for CARDIA black and white women, adjusting for occupation has a negligible effect on the RII, while adjustment for education and income causes reductions of $40 \%$ and $56 \%$ respectively for white women and $26 \%$ and $27 \%$ respectively for black women. For CARDIA white men adjusting for any of the three indicators of objective SES results in comparable reductions in the RII (ranging from $24 \%$ to $31 \%)$.

Whitehall-II men and women also show a greater reduction in the association of SSS and poor global health when occupation is controlled for than when adjusted for education or income $(20 \%$ and $47 \%$ reduction for men and women respectively for occupation versus $15 \%$ and $9 \%$ for women and $21 \%$ and $33 \%$ for men for education and income respectively). In contrast, adjustment for occupation has negligible effect for CARDIA white men, and adjustment for education and for income is more substantial impact (58\% and $47 \%$ reductions, respectively). Similarly the RII for global health is reduced less for black women and men when adjusted for occupation (15\% and $25 \%$ respectively) than when adjusted for education or income (34 and 38\% reductions for black women and 36 and $60 \%$ reductions for black men). The greatest of the RII for white women occurs with adjustment for income (84\%), with smaller reductions for occupation (46\%) and education (35\%).

As predicted, the RII for depression is reduced much more when adjusted for occupation (49\%) than for education (slight increase) or income ( $9 \%$ decrease) for Whitehall-II men. However, for Whitehall-II women the RII increases when adjusted for occupation, as it does for CARDIA white men. The RII also increases when adjusted for education or income for Whitehall-II women but is reduced $3 \%$ and $42 \%$ when adjusted for education and income respectively for CARDIA white men. Black men and women 
and white women in CARDIA generally show greater reductions in the RII when adjusted for income (38-65\%) or education (18-31\%) than for occupation (16-22\%).

Finally, we looked at whether the association of SSS and health is wholly accounted for by objective indicators. The final columns of Tables 5-7 show the RIls for ladder scores when adjusted for all three components of SES. White men in CARDIA are the only group who show an independent association of SSS with hypertension when income, occupation and education are controlled for. All groups, except for Whitehall-II men show an independent association of SSS with depression, and all groups except for CARDIA black men show a significant independent association with general health when income, education, and occupation are controlled for.

\section{SUMMARY AND CONCLUSIONS}

The findings of this study shed light on the relationship of health to subjective social status among British civil servants and whites and blacks in the U.S. , and on the applicability of findings from the Whitehall studies to U.S. populations. The results provide further evidence of a meaningful association of SSS and health. Previous findings from Whitehall-II that lower SSS is related to greater depression and poorer global health (Singh-Manoux et al., 2003) were replicated among both black and white men and women in CARDIA. New analyses revealed that lower ladder scores were also related to higher prevalence of hypertension among all groups except for black men in CARDIA.

SSS was less strongly related to health among blacks than whites in CARDIA. It was unrelated to hypertension for black men and, although significant, was less strongly related to hypertension for CARDIA black versus white women. In addition the association with depression was significantly weaker for black men and women versus their white counterparts; the same was true for global health though differences were 
non-significant. These findings are consistent with previous research (Ostrove et al., 2000) and suggest that social status may be more complex for African Americans. Experiences of discrimination based on one's race/ethnicity may overshadow social status based on socioeconomic factors and weaken the effect of SSS for blacks. Socioeconomic factors may be somewhat less salient in blacks' assessments of their social standing and race-related social experiences may play a relatively greater role.

Different components of socioeconomic status appeared to account for the association of SSS and health by group. In making SSS ratings, participants were asked to consider their occupation, education and income. They could differentially weight these in making a summative judgment and members of the various groups may differ in systematic ways in weights assigned to these components. Specifically, saliency of employment grade to the civil servants may have fostered relatively greater weight placed on that aspect of SES when Whitehall-II subjects made their ladder rankings. Consistent with this, SSS had a stronger association with occupation in Whitehall-II, than in CARDIA. Additionally, occupation accounted for more of the association of SSS with health in Whitehall-II than in CARDIA; and in Whitehall-II, unlike in CARDIA, more of the association of SSS with health was accounted for by occupation than by income or education. One could interpret these differences in varying ways. To the extent that SEI is measured with more error than is employment grade, the occupation measure in CARDIA will less accurately assess conditions of employment and the importance of occupational status to health may be underestimated. Alternatively, use of employment grade in Whitehall-II may overestimate the power of occupation. Insofar as relative status matters for health, the more specific the reference group the greater the association of relative position in that group with health (Deaton, 2003). Whitehall-II subjects operate in a well-defined reference group in which their social position is clear. For the majority of workers who are not part of large, 
hierarchically organized systems, occupational status may be less salient and they may use other groups as their reference group in assessing their relative status.

Occupation played an especially strong role for Whitehall-II men. The impact of occupation on SSS and on the association of SSS and health was weaker and more varied for Whitehall-II women. Employment grade may be somewhat less central to Whitehall women than to men and be less tied to their subjective status. This is consistent with other research showing that women may be relatively more affected by their spouse's socioeconomic position compared to their own and that women's own employment grades have weaker associations with health than does their spouses' grade level (Bartley, Martikainen, Shipley, \& Marmot, 2004).

Contrary to our hypothesis, SSS had a relatively weaker relationship to health among Whitehall-II participants than among whites in CARDIA. One possibility is that the "myth" of classlessness in the U.S. is indeed a myth. The degree of income inequality is similar in the U.S. and England and the growth in inequality has made relative status particularly acute in the U.S. Weaker effects in Whitehall-II could also reflect the more homogenous nature of the Whitehall-II than the CARDIA sample. The former does not include individuals from the highest and lowest socioeconomic strata. At the same time, the Civil Service is a large organization with substantial differences in pay and education across employment grades, and the distribution of SSS scores was similar for Whitehall-II subjects and white CARDIA participants. A third possible explanation for the weaker association of health and SSS for Whitehall-II subjects may lie in the power of the occupational reference group for civil servants. The ladder asks for judgments of one's standing vis-à-vis others in the whole society. Civil servants' positions within Whitehall-II may be more salient and engender more powerful social emotions than does their status in society as a whole. Future research using community samples from England would provide useful data on differences between Whitehall-II 
and nationally representative samples within England as well as comparisons across countries.

SSS was significantly related to depression and perceived health even when adjusted for all components of SES for all groups except for Whitehall-II men for depression and CARDIA black men for perceived health. In contrast, associations of SSS and hypertension became non-significant when adjusted for SES components for all groups except for CARDIA white men where it remained significant. Depression and perceived health are both self-report measures and may share some variation with SSS due to reporting style. It is unlikely that mono-method shared variance accounts for the entire association, however. The significant zero-order relationships between SSS and hypertension for all groups except for black men provides evidence of linkage between SSS and an independently-assessed health outcome; findings reviewed earlier showed such associations in other samples with other biological measures. Global health and depression may be more strongly related to SSS than is hypertension because they capture a broader indication of health for which there are multiple pathways from SSS, while hypertension has a narrower set of mechanisms for its etiology.

The current analyses were limited by the data available in each cohort. One weakness is the age difference between the samples. Even though we controlled for age within each group, Whitehall-II subjects were older than those in CARDIA. The fact that the ladder had only nine rungs in CARDIA and ten in Whitehall-II was dealt with by collapsing into 5 categories in each. Even though the top category had two rungs in Whitehall-II but only one in CARDIA and there could have been somewhat different associations with ladder scores, the distribution of scores did not look markedly different. Despite these differences, the basic findings, apart from those related to the measure of occupation, were similar for Whitehall-II participants and whites in CARDIA. 
In conclusion, the findings lend support to the generalizability of findings from the Whitehall-II studies to European Americans. Whitehall findings may, however, somewhat overestimate the impact of occupation. Greater caution must be used in generalizing to African Americans, not only from Whitehall-II, but also from EuropeanAmerican samples. A strength of CARDIA is its stratification by race since it enrolled enough black subjects to be analyzed as a group. Most studies have inadequate numbers of blacks and either ignore race/ethnicity or control for it. The results of the current study, along with those of previous CARDIA papers, provide further evidence of the importance of looking at processes within each group.

The reasons why SSS shows a weaker association with health among blacks demands further study. It may be that blacks correctly observe that education, income and occupation "buy" them less in the way of advantages than these do for whites. In addition, U.S. blacks are subject to multiple bases of social evaluation which may render their evaluation of socioeconomic standing less important.

In sum, in making their ladder rankings individuals are asked to take into account their education, occupation and income using society as a reference group. Our findings suggest that the resulting judgments are related to their mental and physical health. They appear to make these judgments in relation to the particular context of their lives. In this instance, contextual factors included the objective definition of rank associated with employment grade lived in Whitehall-II and attending to other bases of social status like societal discrimination with which U.S. blacks contend. Future work on health effects of social position should try to capture both the common core as represented by the SSS measure and contextual factors that may modify these judgments. 


\section{References}

Adler, N.E., Epel, E. Castellazzo, G., \& Ickovics, J. (2000). Relationship of subjective and objective social status with psychological and physiological functioning: Preliminary data in healthy white women. Health Psychology, 19(6), 586-592.

Bartley, M., Martikainen, P., Shipley, M., \& Marmot, M. (2004). Gender differences in the relationship of partner's social class to behavioral risk factors and social support in the Whitehall-II study. Social Science \& Medicine, 59, 1925-1936.

Bottomore, T.B. (1965). Classes in modern society. London: Allen \& Unwin.

Cohen, S., Alper, C. M., Doyle, W. J., Adler, N. E., Treanor, J. J. \& Turner, R. B. (in press). Objective and subjective socioeconomic status and susceptibility to the common cold. Health Psychology.

Deaton, A. (2003). Health, inequality, and economic development. Journal of Economic Literature, 41, 113-158.

Dickerson, S. S., Gruenewald, T. L., \& Kemeny, M. E. (2004). When the social self is threatened: Shame, physiology, and health. Journal of Personality 72(6), 11911216.

Duncan, O.D. (1961). A socioeconomic index for all occupations. In A. Reiss, Jr., (Ed.), Occupations and social status (pp. 109-138). New York: Free Press.

Fuhrer, R., Shipley, M. J., Chastang, J. F, Schmaus A., Niedhammer, I., Stansfeld, S. A., et al. (2002), Socioeconomic position, health and possible explanations: A tale of two cohorts. American Journal of Public Health, 92(8), 12901294.

Gianaros, P. J., Horenstein, J. A., Cohen, S., Matthews, K. A., Brown, S. M. Flory, J. D., et al. (2007). Perigenual anterior cingulate morphology covaries with perceived social standing. Social Cognitive \& Affective Neuroscience. Advance access online, doi:10.1093/scan/nsm013.

Goldberg, D. P. (1972). The detection of psychiatric illness by questionnaire. London: Oxford University Press.

Goldman, N., Cornman, J. C., \& Chang, M. C. (2002). Subjective social status: Evaluation of a new instrument. Paper presented at the annual meetings of the Population Association of America, May 1-3, Minneapolis, Minnesota.

Goodman, E., Adler, N. E., Daniels, S. R., Morrison, J. A., Slap, G. B., \& Dolan, L. M. (2003). Impact of objective and subjective social status on obesity in a biracial cohort of adolescents. Obesity Research, 11, 1018-1026.

Hu, P., Adler, N. E., Goldman, N., Weinstein, M., \& Seeman, T. E. (2005). Relationship between subjective social status and measures of health in older Taiwanese persons. Journal of the American Geriatrics Society, 53(3), 483-488. 
Kawachi, I., Daniels, N., \& Robinson, D. E. (2005). Health disparities by race and class: Why both matter. Health Affairs, 24(2), 343-52.

Marmot, M. (2006). Status syndrome: A challenge to medicine. JAMA 296, 395396.

Marmot, M., Ryff, C. D., Bumpass, L. L., Shipley, M., \& Marks, N. F. (1997). Social inequalities in health: Next questions and converging evidence. Social Science \& Medicine, 44, 901-910.

Marmot, M. G., Shipley, M. J., \& Rose, G., (1984). Inequalities in death: Specific explanations of a general pattern. Lancet, 1, 1003-1006. Rutledge.

Oliver, M. \& Shapiro, T. M. (1995). Black wealth/white wealth. New York:

Operario, D., Adler, N. E., \& Williams, D. R. (2004). Subjective social status: Reliability and predictive utility for global health. Psychology \& Health, 19(2), 237-246.

Ostrove, J. M., Adler, N. E., Kuppermann, M., \& Washington, A. E. (2000). Objective and subjective assessments of socioeconomic status and their relationship to self-rated health in an ethnically diverse sample of pregnant women. Health Psychology, 19(6), 613-618.

Papassotiropoulos, A. \& Heun, R. (1999). Screening for depression in the elderly: A study on misclassification by screening instruments and improvement of scale performance. Progress in Neuro-Psychopharmacology \& Biological Psychiatry, 23(3), 431-446.

Radloff, L. S. (1977). The CES-D scale: A self-report depression scale for research in the general population. Applied Psychological Measurement, 1, 385-401.

Singh-Manoux, A., Adler, N. E., \& Marmot, M. G. (2003). Subjective social status: Its determinants and its association with measures of ill-health in the Whitehall-Il study. Social Science and Medicine, 56, 1321-1333.

Singh-Manoux, A., Marmot, M. G., \& Adler, N. E. (2005). Does subjective social status predict health and change in health status better than objective status? Psychosomatic Medicine, 67, 855-861.

Stevens, G. \& Cho, J. H. (1985). Socioeconomic Indices and the New 1980 Census Occupational Classification Scheme. Social Science Research, 14, 142-168.

Williams, D. (1999). Race, socioeconomic status, and health: The added effects of racism and discrimination. In N. E. Adler, M.Marmot, B. McEwen, \& J. Stewart (Eds.). Socioeconomic status and health in industrial nations: Social, psychological, and biological pathways (pp. 173-188), 896. New York: Annals of the New York Academy of Sciences. 
Wright C. E. \& Steptoe A. (2005). Subjective socioeconomic position, gender and cortisol responses to waking in an elderly population. Psychoneuroendocrinology, 30(6), 582-590. 
Table 1.

Distribution (number and percent) of subjective social status rankings in CARDIA (by sex and race) and in Whitehall-II (by sex)

\begin{tabular}{|c|c|c|c|c|c|c|}
\hline & \multicolumn{6}{|c|}{ Ladder ranking } \\
\hline & \multicolumn{4}{|c|}{ Low status } & \multicolumn{2}{|c|}{ High status } \\
\hline & 1 and 2 & 3 and 4 & 5 and 6 & 7 and 8 & 9 and 10 & $N$ \\
\hline \multicolumn{7}{|l|}{ Women } \\
\hline \multicolumn{7}{|l|}{ CARDIA } \\
\hline Black & $63(6.3)$ & $203(20.2)$ & $518(51.6)$ & $173(17.3)$ & $46(4.6)$ & 1003 \\
\hline White & $18(1.8)$ & $132(12.9)$ & $487(47.5)$ & $366(35.7)$ & $22(2.2)$ & 1025 \\
\hline Whitehall-II & $29(1.2)$ & $293(12.4)$ & $872(36.8)$ & 991 (41.8) & $187(7.9)$ & 2372 \\
\hline \multicolumn{7}{|l|}{ Men } \\
\hline \multicolumn{7}{|l|}{ CARDIA } \\
\hline Black & $31(4.4)$ & $143(20.3)$ & $351(49.9)$ & $141(20.1)$ & $37(5.3)$ & 703 \\
\hline White & $12(1.3)$ & $89(9.9)$ & $361(40.1)$ & 397 (44.1) & $42(4.7)$ & 901 \\
\hline Whitehall-II & $65(1.4)$ & $627(13.6)$ & $1732(37.6)$ & 1918 (41.6) & $267(5.8)$ & 4609 \\
\hline
\end{tabular}


Table 2.

Correlation (Pearson) among education, occupation and income and between these and ladder scores for six groups

\begin{tabular}{|c|c|c|c|c|c|c|}
\hline \multirow[b]{2}{*}{ Group } & \multicolumn{3}{|c|}{ Intercorrelations between } & \multicolumn{3}{|c|}{ Correlations with SSS } \\
\hline & $\begin{array}{l}\text { Education- } \\
\text { occupation }\end{array}$ & $\begin{array}{l}\text { Income- } \\
\text { occupation }\end{array}$ & $\begin{array}{l}\text { Education- } \\
\text { income }\end{array}$ & Occupation & Education & Income \\
\hline $\begin{array}{l}\text { CARDIA black } \\
\text { women }\end{array}$ & 0.51 & 0.38 & 0.42 & 0.15 & 0.19 & 0.19 \\
\hline $\begin{array}{l}\text { CARDIA white } \\
\text { women }\end{array}$ & 0.52 & 0.35 & 0.36 & 0.28 & 0.32 & 0.51 \\
\hline Whitehall-II women & 0.56 & 0.66 & 0.47 & 0.56 & 0.40 & 0.45 \\
\hline CARDIA black men & 0.55 & 0.45 & 0.48 & $0.11^{*}$ & 0.18 & 0.23 \\
\hline CARDIA white men & 0.65 & 0.42 & 0.42 & 0.35 & 0.40 & 0.53 \\
\hline Whitehall-II men & 0.51 & 0.66 & 0.44 & 0.58 & 0.39 & 0.46 \\
\hline
\end{tabular}

${ }^{*} p<0.01$.

All others significant at $\rho<0.001$. 
Table 3.

Regressions predicting SSS: partial $R^{2}$ for education, income and occupation and $R^{2}$ for model

\begin{tabular}{|c|c|c|c|c|c|c|}
\hline & \multicolumn{2}{|l|}{ CARDIA } & \multirow{2}{*}{$\begin{array}{l}\text { Whitehall-II } \\
\text { Women }\end{array}$} & \multicolumn{2}{|l|}{ CARDIA } & \multirow{2}{*}{$\begin{array}{l}\text { Whitehall-II } \\
\text { Men }\end{array}$} \\
\hline & Black women & White women & & Black men & White men & \\
\hline Education & 0.05 & 0.03 & 0.13 & $0.01^{=t}$ & 0.05 & 0.11 \\
\hline Income & 0.02 & 0.28 & 0.13 & 0.06 & 0.31 & 0.13 \\
\hline Occupation & $0.00^{*}$ & $0.00^{*}$ & 0.44 & $0.00^{*}$ & $0.00^{*}$ & 0.47 \\
\hline
\end{tabular}

"Not significant.

${ }^{*} p<0.01$.

All others significant $\rho<0.0001$. 


\begin{tabular}{|c|c|c|c|c|c|c|}
\hline & \multicolumn{4}{|c|}{ Low status } & \multicolumn{2}{|c|}{ High status } \\
\hline & 1 and 2 & 3 and 4 & 5 and 6 & 7 and 8 & 9 and 10 & Significance of trend \\
\hline \multicolumn{7}{|l|}{ Hypertension } \\
\hline CARDIA black women & 36.67 & 36.95 & 29.70 & 27.38 & 25.00 & $\rho \leq 0.02$ \\
\hline CARDIA white women & 22.22 & 16.92 & 11.67 & 6.13 & 9.52 & $\rho \leq 0.01$ \\
\hline Whitehall-II women & 27.50 & 25.85 & 17.32 & 17.81 & 19.71 & $\rho \leq 0.01$ \\
\hline CARDIA black men & 31.03 & 30.07 & 29.68 & 38.41 & 29.73 & $\rho \leq 0.33$ \\
\hline CARDIA white men & 33.33 & 31.46 & 24.30 & 18.07 & 11.90 & $\rho \leq 0.01$ \\
\hline Whitehall-II men & 27.85 & 29.21 & 27.14 & 24.85 & 25.73 & $\rho \leq 0.02$ \\
\hline \multicolumn{7}{|l|}{ Fair/poor global health } \\
\hline CARDIA black women & 41.27 & 17.73 & 9.65 & 7.51 & 6.52 & $\rho \leq 0.001$ \\
\hline CARDIA white women & 27.78 & 20.45 & 6.16 & 3.83 & 0 & $\rho \leq 0.001$ \\
\hline Whitehall-II women & 44.33 & 24.64 & 12.84 & 8.34 & 4.21 & $\rho \leq 0.001$ \\
\hline CARDIA black men & 32.26 & 14.69 & 11.97 & 8.51 & 5.41 & $\rho \leq 0.001$ \\
\hline CARDIA white men & 25.00 & 15.73 & 6.09 & 3.53 & 2.38 & $\rho \leq 0.001$ \\
\hline Whitehall-II men & 42.12 & 26.67 & 15.72 & 9.14 & 4.70 & $\rho \leq 0.001$ \\
\hline \multicolumn{7}{|c|}{ CES-D depression > 16 or GHQ ${ }^{2}$ cases $^{*}$} \\
\hline CARDIA black women & 61.90 & 35.35 & 21.89 & 18.24 & 19.57 & $\rho \leq 0.001$ \\
\hline CARDIA white women & 50.00 & 33.33 & 10.72 & 7.99 & 14.29 & $\rho \leq 0.001$ \\
\hline Whitehall-II women & 47.75 & 24.50 & 13.10 & 7.84 & 3.99 & $\rho \leq 0.001$ \\
\hline CARDIA black men & 51.61 & 25.87 & 13.26 & 12.77 & 21.62 & $\rho \leq 0.001$ \\
\hline CARDIA white men & 16.67 & 22.47 & 9.47 & 7.63 & 7.14 & $\rho \leq 0.001$ \\
\hline Whitehall-II men & 42.76 & 22.89 & 15.29 & 8.79 & 10.52 & $\rho \leq 0.001$ \\
\hline
\end{tabular}


Table 5 .

Relative Index of Inequality (RII) of SSS on hypertensionadjusted for age, occupation, education and income in Whitehall-II men and women and CARDIA black and white men and women

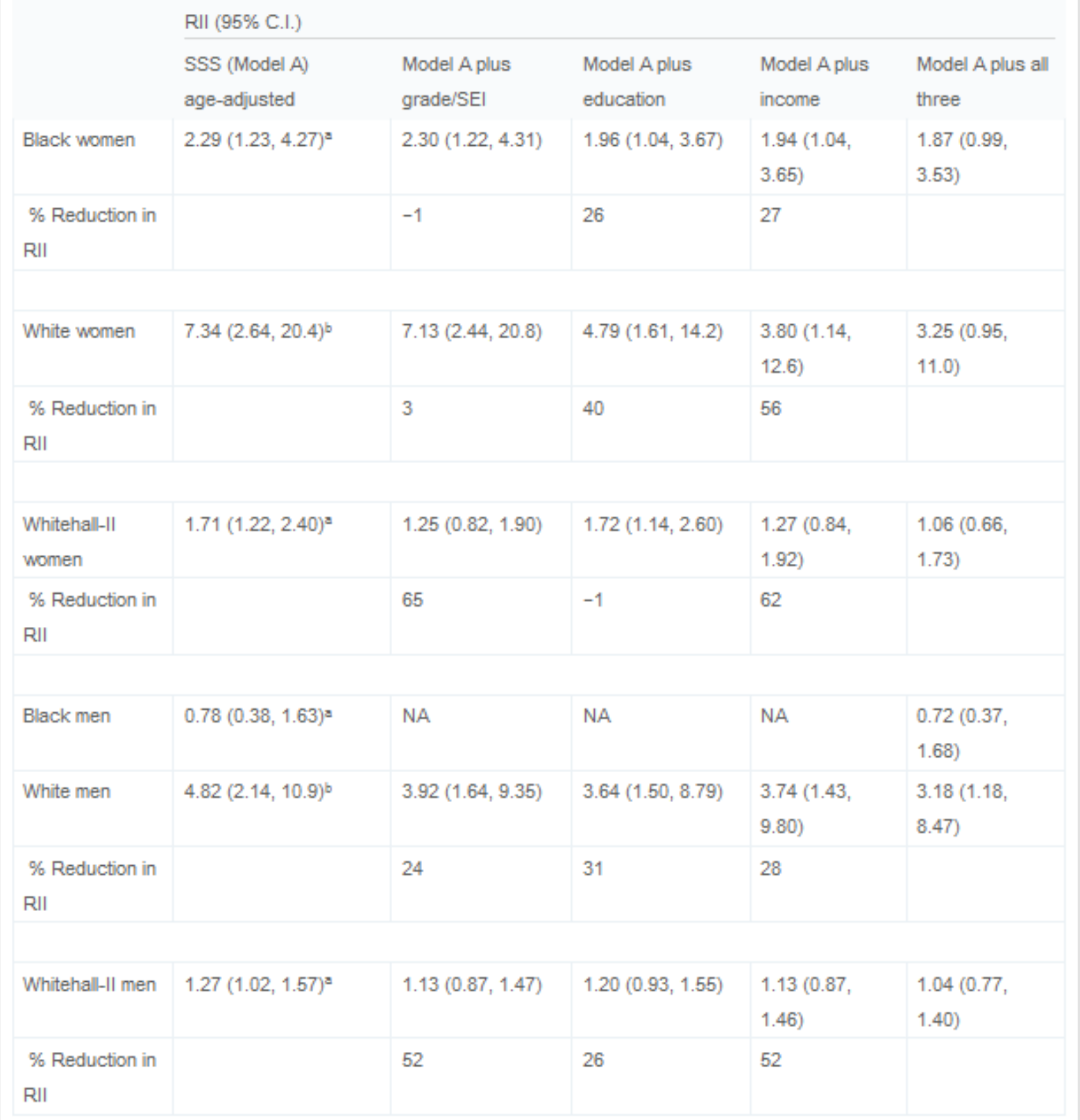

For Model A, groups with different subscripts within sex, are significantly different from one another. 


\begin{tabular}{|c|c|c|c|c|c|}
\hline \multicolumn{6}{|c|}{$\begin{array}{l}\text { Table } 6 . \\
\text { Relative Index of Inequality (RII) of SSS on perceived global health adju } \\
\text { Whitehall-II men and women and CARDIAblack and white men and women }\end{array}$} \\
\hline & \multicolumn{5}{|l|}{ RII (95\% C.I.) } \\
\hline & $\begin{array}{l}\text { SSS (Model A) } \\
\text { age-adjusted }\end{array}$ & $\begin{array}{l}\text { Model A plus } \\
\text { occupation }\end{array}$ & $\begin{array}{l}\text { Model A plus } \\
\text { education }\end{array}$ & $\begin{array}{l}\text { Model A plus } \\
\text { income }\end{array}$ & $\begin{array}{l}\text { Model A plus all } \\
\text { three }\end{array}$ \\
\hline Black women & $21.31(8.61,52.8)^{\mathrm{s}}$ & $18.20(7.28,45.6)$ & $14.38(5.78,35.8)$ & $\begin{array}{l}13.66(5.50 \\
33.9)\end{array}$ & $\begin{array}{l}11.95 \text { (4.83, } \\
29.6)\end{array}$ \\
\hline $\begin{array}{l}\text { \% Reduction in } \\
\text { RII }\end{array}$ & & 15 & 34 & 38 & \\
\hline White women & $43.3(12.9,145.2)^{\mathrm{a}}$ & $23.73(6.73,83.6)$ & $\begin{array}{l}28.45(7.94 \\
101.9)\end{array}$ & $\begin{array}{l}7.94(1.94, \\
32.6)\end{array}$ & $\begin{array}{l}6.88(1.63 \\
29.1)\end{array}$ \\
\hline $\begin{array}{l}\text { \% Reduction in } \\
\text { RII }\end{array}$ & & 46 & 35 & 84 & \\
\hline $\begin{array}{l}\text { Whitehall-II } \\
\text { women }\end{array}$ & $3.76(2.27,6.22)^{b}$ & $3.21(1.7,06.10)$ & $3.36(1.86,6.09)$ & $\begin{array}{l}3.51(1.95 \\
6.32)\end{array}$ & $\begin{array}{l}3.37(1.69 \\
6.72)\end{array}$ \\
\hline $\begin{array}{l}\text { \% Reduction in } \\
\text { RII }\end{array}$ & & 20 & 15 & 9 & \\
\hline Black men & $5.89(2.05,16.9)^{a, b}$ & $4.67(1.64,13.3)$ & $4.05(1.41,11.6)$ & $\begin{array}{l}3.01(1.05 \\
8.61)\end{array}$ & $\begin{array}{l}2.80(0.98 \\
8.01)\end{array}$ \\
\hline $\begin{array}{l}\text { \% Reduction in } \\
\text { RII }\end{array}$ & & 25 & 36 & 60 & \\
\hline White men & $23.56(6.19,89.7)^{\mathrm{a}}$ & $23.36(5.51,98.9)$ & $10.50(2.45,45.1)$ & $\begin{array}{l}12.88(2.60 \\
63.8)\end{array}$ & $\begin{array}{l}9.20(1.81 \\
46.9)\end{array}$ \\
\hline $\begin{array}{l}\text { \% Reduction in } \\
\text { RII }\end{array}$ & & 1 & 58 & 47 & \\
\hline Whitehall-II men & $4.16(2.97,5.83)^{b}$ & $2.69(1.80,4.03)$ & $3.51(2.38,5.18)$ & $\begin{array}{l}3.12(2.14, \\
4.55)\end{array}$ & $\begin{array}{l}2.28(1.47 \\
3.56)\end{array}$ \\
\hline $\begin{array}{l}\text { \% Reduction in } \\
\text { RII }\end{array}$ & & 47 & 21 & 33 & \\
\hline
\end{tabular}

For Model A, groups with different subscripts within sex, are significantly different from one another. 


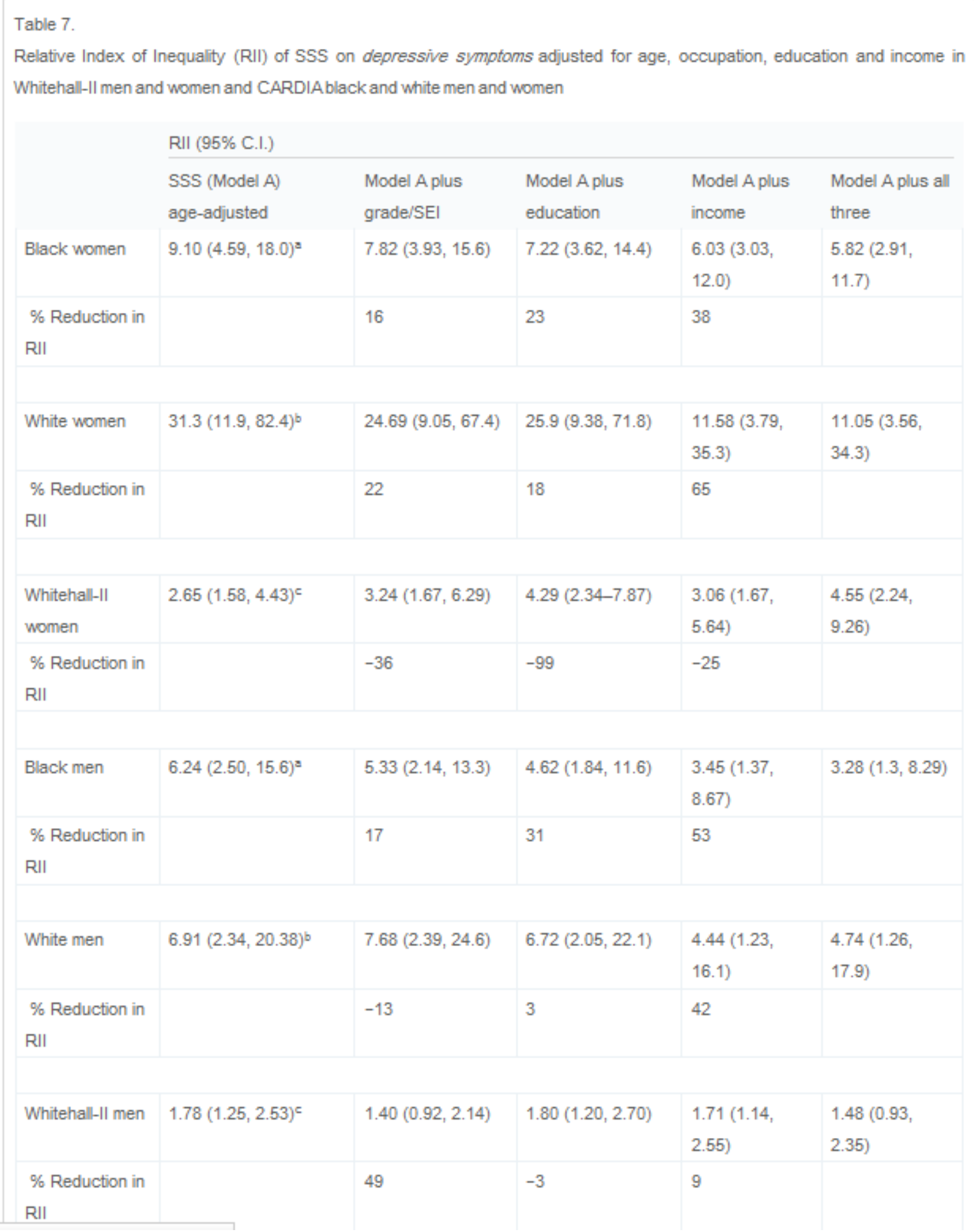

For Model A, groups with different subscripts within sex, are significantly different from one another. 